\title{
PENGARUH KINERJA PENCIPTAAN NILAI, BAURAN PROMOSI, BUKTI JASA TERHADAP CITRA TAMAN REKREASI DALAM RANGKA PENGEMBANGAN CITRA JAKARTA SEBAGAI GREEN CITY
}

\author{
Mudji Sabar
}

\begin{abstract}
Abstrak
This research was directed by the fact that Recreation Parks in Jakarta had not been optimising their performance so far. The total number of visitors of the Recreation Parks was not straightly in line with the total number of visitors to Jakarta. Tourists coming to Jakarta, both domestic and international, increased significantly year by year, whereas visitors of the Recreation Parks was fluctuating and decreasing since 2004. The main cause of this condition was the low performance of the corporate image of the Recreation Parks as perceived by the visitors. Accordingly, this research was focused on the efforts to increase the corporate image by analysing the attempts to upgrade the quality of value creation, promotion mix, and the evidence of service done by the Recreation Parks. The locus of this research was Jakarta the metropolitan city as one of the prime tourist destinations in Indonesia. By this choice, it is hoped that the result of this research would be applicable to all other destinations in Indonesia. The descriptive analysis was employed to uncover the performance of value creation, promotion mix, the evidence of service, and the corporate image of the Recreation Parks. The explanative analysis would statistically explain the relationship among variables, either simultaneuosly or individually, as well as identify the significant influence of each independent variable towards dependent variable. This research was aimed to search the visitors' perception; therefore, the unit analysis of this research was consequently the visitors of the Recreation Parks in Jakarta. The charateristics of the chosen respondents were domestic visitors, adult, repeat visitors, and visitors who have ever visited all the 3 Recreation Parks in Jakarta. Data collection was done through observation, interview, and questioner addressed to 429 respondents. Data analysis was executed by path analysis. This research showed that the dominant influencing variable to increase the corporate image of the Recreation Parks was the evidence of service, mainly the physical evidence dimension. Moreover, it was identified that there were 2 solution factors in line with the concept of green tourism to be adopted to fasten the realization of Jakarta as a green city, ie green space and physical fasilities. In this case, the local government of Jakarta should widen the the area of green open space, improve the city's drainage system, implement the city's integrated garbage management, provide cheap and comfortable public transportation, execute emission control, diseminate soccial norms in line with the green tourism concept.
\end{abstract}

Key Words $\quad$ : Value Creation, Promotion Mix, the Evidence of Service, the Image of Recreation Parks, and Green City

\section{PENDAHULUAN}

\section{Latar Belakang}

Taman Rekreasi merupakan salah satu daya tarik wisata yang berfungsi untuk mengembalikan kesegaran jasmani dan rohani bagi masyarakat melalui fasilitas yang disediakan yang mengandung unsur pendidikan, hiburan, dan kebudayaan serta pelestarian lingkungan (Keputusan Menteri Pariwisata, Pos dan Telekomunikasi Nomor . KM. 70/PW.105/MPPT-
85). Fungsi-fungsi tersebut mendorong minat penulis untuk menjadikan Taman Rekreasi sebagai objek penelitian ini. Dipilihnya lokus penelitian di Jakarta didasarkan pertimbangan karena posisi Jakarta sebagai destinasi wisata utama di Indonesia sehingga diharapkan bahwa hasil peneltian ini nantinya dapat diimplementasikan di destinasi-destinasi lainnya di Indonesia.

Ditilik dari sisi pengunjung, keberadaan Taman Rekreasi dapat digolongkan sebagai daya tarik wisata terfavorit di DKI Jakarta, bahkan

Pengaruh Kinerja Penciptaan Nilai, Bauran Promosi, Bukti Jasa Terhadap Citra Taman Rekreasi Dalam Rangka

Pengembangan Citra Jakarta sebagai Green City 
menempati urutan pertama (Taman Impian Jaya Ancol/TIJA), ke-2 (Taman Mini Indonesia Indah/TMII), dan ke-4 (Taman Margasatwa Ragunan/TMR), sedangkan urutan ke-3 ditempati oleh Pulau Seribu (Dinas Pariwisata Provinsi DKI Jakarta, Laporan dan Analisis Data Kepariwisataan 2008). Berikut disajikan data pengunjung Taman Rekreasi Tahun2003-2008.

Tabel 1

Total Kunjungan Taman Rekreasi Jakarta Tahun 2003-2008

\begin{tabular}{|c|c|c|c|c|c|c|}
\hline $\begin{array}{c}\text { Daya } \\
\text { Tarik } \\
\text { Wisata }\end{array}$ & $\mathbf{2 0 0 3}$ & $\mathbf{2 0 0 4}$ & $\mathbf{2 0 0 5}$ & $\mathbf{2 0 0 6}$ & $\mathbf{2 0 0 7}$ & $\mathbf{2 0 0 8}$ \\
\hline TIJA & 12.051 .106 & 10.088 .300 & 10.121 .251 & 10.795 .273 & 13.377 .011 & 13.567 .630 \\
\hline TMII & 4.217 .896 & 4.874 .089 & 4.108 .369 & 4.092 .932 & 3.808 .176 & 4.510 .679 \\
\hline TMR & 3.121 .677 & 3.358 .740 & 2.050 .055 & 2.553 .087 & 3.392 .223 & 3.319 .186 \\
\hline Total & 19.390 .679 & 18.321 .129 & 16.279 .675 & 17.441 .292 & 20.577 .410 & 21.397 .495 \\
\hline
\end{tabular}

Sumber: Diolah dari Laporan dan Analisis Data Kepariwistaan,Dinas Pariwisata Provisi DKI Jakarta 2008

Berdasarkan data pada tabel diatas, maka dapat disimpulkan bahwa jumlah pengunjung Taman Rekreasi sesungguhnya mengalami proses fluktuasi dan cenderung menurun sejak Tahun 2004 sampai dengan 2006 kemudian naik lagi pada Tahun 2007-2008. Jika dibandingkan antara total wisatawan ke Provinsi DKI Jakarta dengan total pengunjung Taman Rekreasi Jakarta, maka dapat diidentifikasi terjadinya kesenjangan; wisatawan yang berkunjung ke Jakarta terus naik, sementara pengunjung Taman Rekreasi justru berfluktuasi. Tabel berikut menunjukkan total kunjungan wisatawan ke DKI Jakarta.

Tabel 2

Kunjungan Wisatawan ke DKI Jakarta Tahun 2003-2008

\begin{tabular}{|c|c|c|c|c|}
\hline TAHUN & $\begin{array}{l}\text { WISMAN } \\
\text { KE DKI } \\
\text { JAKARTA }\end{array}$ & $\begin{array}{c}\text { PERT } \\
\text { UMBU } \\
\text { HAN }\end{array}$ & $\begin{array}{l}\text { WISNUS } \\
\text { KE DKI } \\
\text { JAKARTA }\end{array}$ & $\begin{array}{c}\text { PERTU } \\
\text { MBUH } \\
\text { AN }\end{array}$ \\
\hline 2003 & 1.125 .168 & - & 9.088 .420 & - \\
\hline 2004 & 1.065 .495 & $(5,30)$ & 13.577 .000 & 49,36 \\
\hline 2005 & 1.168 .656 & 9,68 & 11.746 .250 & $(13,48)$ \\
\hline 2006 & 1.216 .132 & 4,06 & 12.777 .571 & 8,78 \\
\hline 2007 & 1.216 .057 & $(0,01)$ & 14.055 .328 & 10,00 \\
\hline 2008 & 1.534 .785 & 26,21 & 15.741 .967 & 12,00 \\
\hline $\begin{array}{l}\text { Rata-Rata } \\
\text { Pertumbuhan }\end{array}$ & & 6,93 & & 13,33 \\
\hline $\begin{array}{l}\text { Sumber } \\
\text { Kepariwisa } \\
\text { Jakarta, 20 }\end{array}$ & $\begin{array}{r}\text { Lapo } \\
\text { Dinas }\end{array}$ & Pariv & Anali & $\begin{array}{r}\text { Data } \\
\text { DKI }\end{array}$ \\
\hline
\end{tabular}

Jika dilihat dari aspek pertumbuhan, maka rata-rata pertumbuhan pengunjung Taman
Rekreasi adalah 2,42\% per tahun, sementara itu rata-rata pertumbuhan kunjungan wisatawan mancanegara (wisman) ke Provinsi DKI Jakarta adalah $6,93 \%$ per tahun, dan rata-rata pertumbuhan kunjungan wisatawan nusantara (wisnus) ke Provinsi DKI Jakarata adalah 13,33\% per tahun. Hal ini mempertegas adanya kesenjangan antara pengunjung Taman Rekreasi di DKI Jakarta (sebagai daya tarik wisata) dengan pengunjung Provinsi DKI Jakarta (destinasi wisata).

Kesenjangan tersebut mencerminkan adanya masalah pada citra Taman Rekreasi di Jakarta. Gronroos, Christian dalam Service Management and Marketing : Customer Management in Service Competition menyatakan bahwa citra perusahaan bisa mempengaruhi persepsi pelanggan terhadap produk atau jasa yang ditawarkan. Apabila citra perusahaan tersebut positif, maka persepsi pelanggan terhadap produk atau jasa yang ditawarkan perusahaan tersebut juga akan semakin positif. Akibatnya, pelanggan akan cenderung loyal terhadap perusahaan tersebut, bahkan akan menyebarkan berita positif kepada koleganya (Gronroos, 2007 : 341-342). Sedangkan dimensi citra menurut pandangan Aaker, David dalam Managing Brand Equity : Capitalizing on the Value of a Brand Name (2001 : 17) dan Yasin, Norjaya Mohd; Noor, Mohd Nasir; Mohamad, Osman dalam Journal of Product and Brand Management (2007) terdiri dari brand awareness, perceived quality, brand association, brand loyalty, dan brand distinctivness.

Kriteria Taman Rekreasi sebagaimana yang diharapkan oleh Keputusan Menteri Pariwisata, Pos dan Telekomunikasi No. KM.70/PW.105/MPPT-85 belum dipenuhi secara maksimal oleh ketiga Taman Rekreasi di Jakarta, antara lain : kondisi tampilan fasilitas fisik yang belum menimbulkan kesan awal positif (positive first impression) bagi pengunjung, keadaan di sekitar Taman Rekreasi yang belum bebas polusi, kebersihan di dalam dan di sekitar Taman Rekreasi yang masih harus ditingkatkan, kenyamanan pengunjung (terutama pada peak season) yang juga masih harus ditingkatkan. Zeithaml, Bitner, Gremler dalam Service Marketing : Integrating Customer Focus Across the Firm (2006 : 132) menyatakan bahwa Bukti Jasa (the Evidence of Service) yang terdiri dari people, process, dan physical evidence merupakan 
elemen-elemen tangible yang dimanfaatkan konsumen untuk menilai sebuah jasa yang bersifat intangible. Hal-hal kasat mata sebagaimana teridentifikasi di atas sangat berpengaruh terhadap persepsi pengunjung terhadap jasa yang ditawarkan Taman Rekreasi yang selanjutnya berpengaruh terhadap citra Taman Rekreasi.

Pengembangan produk pun terkesan kurang mendapat perhatian, hanya TIJA yang terkesan dinamis, sementara TMII dan TMR kurang dinamis dalam pengembangan produk, sehingga terkesan monoton. Seiring dengan makin dicarinya service value yang lebih tinggi, maka sebagian masyarakat mulai mencari alternatif rekreasi di tempat lain, bahkan ke luar negeri (seperti : Singapore, Malaysia, Thailand, dan China), apalagi didukung dengan adanya low cost airlines ke destinasi-destinasi tersebut. Kondisi tersebut menyiratkan bahwa Taman Rekreasi belum mampu memberikan competitive benefit bagi pengunjungnya. Goodman, Steven dalam Competetive Benefit : An Outcome Approach to Marketing in the New Economy menyatakan bahwa penciptaan nilai (value creation) adalah proses pertukaran sumber daya yang dapat meningkatkan kemanfaatan atau memberikan competitive benefit kepada pihakpihak yang terlibat. Goodman menawarkan TCCR map dalam rangka proses penciptaan nilai yang terdiri dari dimensi Time Compression, Core Competency, Continuous Improvement, dan Relationships.

Aspek komunikasi pemasaran juga belum secara maksimal dilaksanakan oleh Taman Rekreasi untuk memperkenalkan jasa yang ditawarkan. Berdasarkan wawancara dengan pengelola Taman Rekreasi (2006), ditemu-kenali bahwa komunikasi pemasaran belum dilaksanakan secara komprehensif. Tidak semua pengunjung mengetahui adanya hal-hal baru yang dikembangkan/dilaksanakan oleh Taman Rekreasi. Hampir 30\% pengunjung TMII tidak mengetahui wahana baru di TMII, 20\%-30\% hanya meminati Sky Lift dan Keong Mas, acara musik yang digelar di TMII hanya diketahui oleh sebagian kecil orang (observasi terhadap sejumlah internal survey TMII 2006). Hasil internal survey TIJA 2002 menyatakan bahwa 40\% pengunjung Ancol tidak mengetahui seluruh fasilitas yang disediakan oleh manajemen TIJA (Bidang Riset PT Pembangunan Jaya Ancol, 2002). TMR memiliki pusat Primata yang terkenal di dunia, akan tetapi hanya sebagian kecil masyarakat yang mengetahui hal tersebut (wawancara dengan pengelola TMR, 2006).

Berdasarkan uraian $\mathrm{di}$ atas dapat diidentifikasi bahwa citra Taman Rekreasi masih rendah yang dipengaruhi oleh masih rendahnya kinerja value creation, bauran promosi, dan bukti jasa. Berdasarkan hal tersebut, maka tujuan penelitian ini adalah :

1) Menguji persepsi pengunjung terhadap kinerja Penciptaan Nilai (Value Creation), Bauran Promosi (Promotion Mix), Bukti Jasa (the Evidence of Service), dan Citra (Company Image) Taman Rekreasi di Jakarta;

2) Menguji pengaruh kinerja Penciptaan Nilai (Value Creation), Bauran Promosi (Promotion Mix), dan Bukti Jasa (the Evidence of Service) terhadap Citra (Company Image)Taman Rekreasi di Jakarta, baik secara simultan maupun parsial;

Memperoleh hasil penelitian yang dapat diimplementasikan untuk mendorong realisasi pengembangan Jakarta sebagai Green City sekaligus sebagai bahan pemecahan masalah (tidak diverifikasi).

\section{KERANGKA PEMIKIRAN}

Berdasarkan uraian pada latar belakang penelitian telah diidentifikasi bahwa permasalahan yang dihadapi oleh Taman Rekreasi adalah masalah citra yang belum sesuai dengan harapan pengunjung. Pada hakikatnya citra Taman Rekreasi dapat berubah seiring dengan dinamika persepsi pengunjung. Fungsi-fungsi yang disandang Taman Rekreasi merupakan janji yang harus dipenuhi yang mencakup : fungsi sebagai sarana edukasi, rekreasi, relaksasi (hiburan) dan pelestari (lingkungan). Penilaian terhadap pelaksanaan fungsi-fungsi inilah yang membentuk persepsi pengunjung terhadap citra Taman Rekreasi yang terbangun berdasarkan 2 hal utama, yaitu pengalaman berkunjung (experience) dan informasi yang diperoleh. Dari pengalaman berkunjung akan diperoleh kesan tentang kualitas jasa Taman Rekreasi (what) dan bagaimana jasa tersebut disampaikan kepada pengunjung (how). Dari aspek what juga akan diperoleh kesan apakah Taman Rekreasi tersebut menawarkan hal-hal baru atau tidak (inovasi). Disamping itu kesan

Pengaruh Kinerja Penciptaan Nilai, Bauran Promosi, Bukti Jasa Terhadap Citra Taman Rekreasi Dalam Rangka

Pengembangan Citra Jakarta sebagai Green City

63- 86 
pengunjung terhadap citra Taman Rekreasi juga bisa dibangun dari informasi yang diperoleh, baik yang bersumber dari komunikasi pemasaran maupun yang bersumber dari word-of-mouth (keluarga, teman, relasi). Secara teoritik dapat diidentifikasikan bahwa citra Taman Rekreasi dipengaruhi oleh beberapa variabel bebas, yaitu : bukti jasa, penciptaan nilai, dan bauran promosi.

Bukti Jasa (the Evidence of Service) merupakan kesan atau penilaian pengunjung terhadap jasa Taman Rekreasi yang telah dinikmatinya berdasarkan kinerja people, process, dan physical evidence. Dimensi 3Ps inilah yang merupakan sarana tangible yang digunakan pengunjung untuk menilai jasa Taman Rekreasi yang bersifat intangible. Parasuraman, Leonard $\mathrm{L}$ Berry dan Valerie A Zeithaml (1997:26) dalam model gap kualitas jasa menmyatakan bahwa sering terjadi kesenjangan dalam bisnis jasa yang bermuara kepada citra perusahaan. Pertama, adanya kesenjangan antara standar kualitas yang dibuat oleh perusahaan

dengan penyampaian jasa (GAP 3). Kedua, adanya kesenjangan antara sistem penyampaian jasa dengan program bauran promosi (GAP 4). Apabila kesenjangan ini sering terjadi dan selalu menimbulkan ketidak-puasan pengunjung, maka citra Taman Rekreasi akan semakin negatif di benak pengunjung.

Penciptaan nilai, pada prinsipnya, merupakan upaya Taman Rekreasi untuk memperbaiki pengalaman berkunjung (memberikan pengalaman baru bagi pengunjung) dengan cara memberikan sesuatu yang baru. Apabila kondisi ini dapat direalisasikan, maka pengunjung akan merasa mendapatkan nilai (value) yang lebih baik dibanding yang diberikan oleh pesaing (suoerior value). Apabila hal ini dapat di-maintain secara berkelanjutan, maka citra Taman Rekreasi akan semakin positif di benak pengunjung. Dalam upaya untuk menciptakan nilai (creating value), pengelola Taman Rekreasi perlu meningkatkan 4 komponen penciptaan nilai sebagaimana yang dikemukakan oleh Goodman, Steven (2004), yaitu sebagai berikut time compression, core competence, continuous improvement, relationship.

Komunikasi pemasaran merupakan komunikasi eksternal yang disampaikan oleh perusahaan kepada target audience melalui berbagai media. Pesan yang disampaikan pada intinya memuat janji tentang produk/jasa yang ditawarkan sebagai solusi terbaik bagi kebutuhan target pasar. Komunikasi eksternal ini harus diimbangi dengan komunikasi internal agar karyawan dapat melaksanakan service delivery sesuai standar yang ditetapkan. Ketidakpuasan bisa terjadi karena adanya kesenjangan antara janji yang dibuat (melalui komunikasi eksternal) dengan pemenuhan janji tersebut (melalui service delivery).

Zeithaml, et.al, mengidentifikasikan beberapa faktor yang melatarbelakangi terjadi kesenjangan tersebut (Zeithaml, et.al., $2006:$ 42), yaitu sebagai berikut :

1) Kurang terintegrasikannya komunikasi pemasaran jasa;

2) Tidak efektifnya manajemen harapan pelanggan;

3) Janji yang melampaui batas (overpromising);

4) Kurang memadainya komunikasi horisontal (antar fungsi bisnis).

Apabila pandangan Zeithaml et.el. tersebut diperhatikan dan komunikasi pemasaran dilaksanakan secara tepat dan benar, maka akan dapat membangun citra positif Taman Rekreasi.

Dalam rangka pengembangan Jakarta sebagai green city pada hakikatnya adalah upaya pembangunan citra Jakarta sebagai destinasi pariwisata peduli lingkungan. Dalam kaitan ini, temuan hasil penelitian yang bersentuhan dengan konsep green tourism dapat diadopsi untuk mendorong realisasi pengembangan citra Jakarta sebagai green city. Citra destinasi (Jakarta) dan citra daya tarik wisata (Taman Rekreasi) saling mempengaruhi satu sama lain. Oleh karena itu, apabila citra Jakarta sebagai green city sudah terbangun kuat, maka akan memperkuat citra Taman Rekreasi, begitu juga sebaliknya.

Berdasarkan uraian kerangka pemikiran di atas maka dapat dirumuskan paradigma penelitian sebagai berikut : 


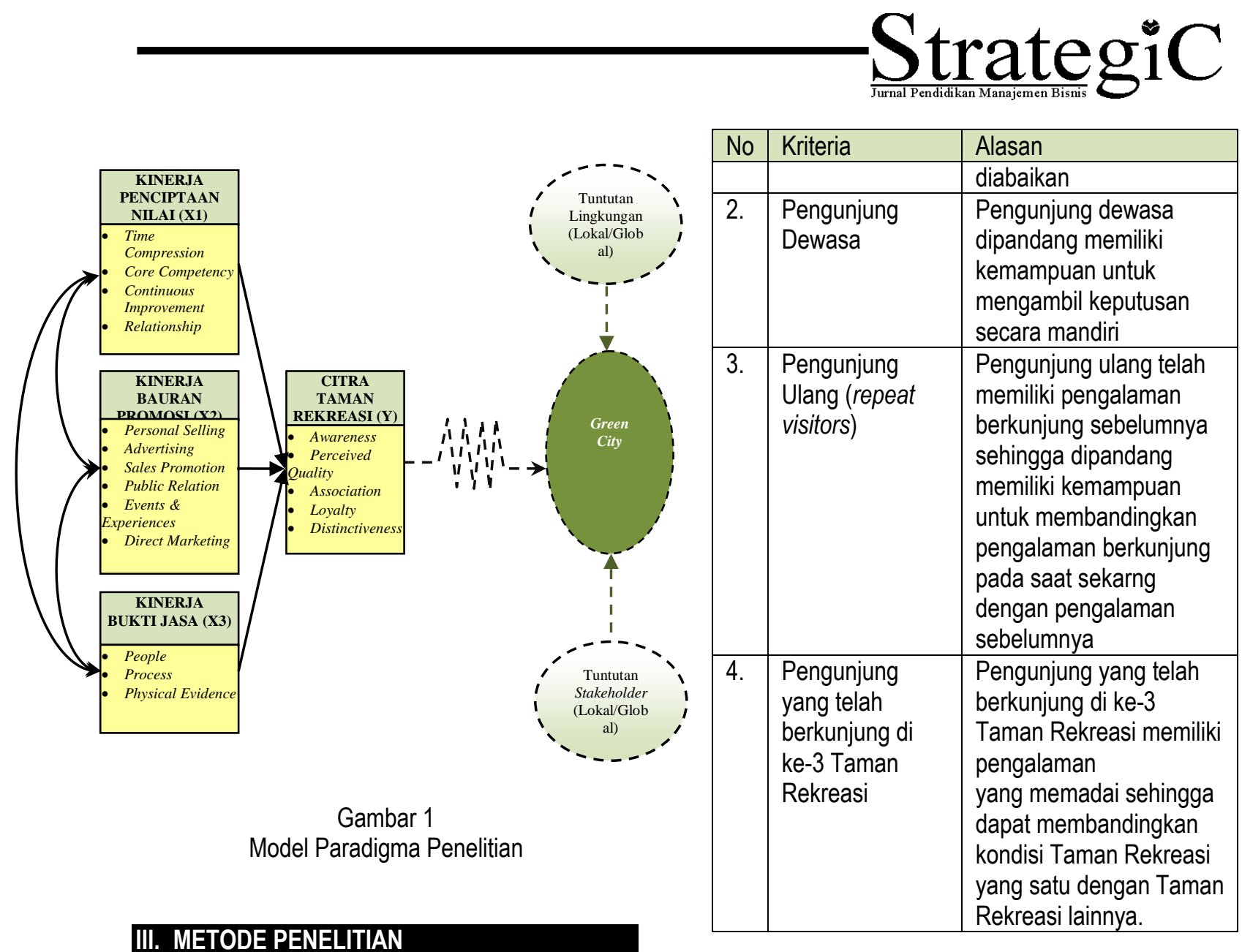

Penelitian ini bersifat deskriptif dan verifikatif yang digunakan untuk mengukur kinerja masing-masing variabel penelitian dan menguji pengaruh kinerja penciptaan nilai, bauran promosi, dan bukti bukti jasa terhadap citra Taman Rekreasi baik secara simultan maupun parsial. Untuk mengukur kinerja variabel penelitian melalui analisis deskriptif, terlebih dahulu dibuat zonasi kinerja, yaitu : sangat tinggi (skor 4-5), tinggi (skor 3-4), rendah (skor 2-3), dan sangat rendah (skor 12). Pengujian analisis verifikatif dilakukan dengan cara menentukan penerimaan atau penolakan hipotesis dan menghitung besarnya koefisien pengaruh variabel bebas terhadap variabel terikat melalui path analysis atau analisis jalur. Unit analisis dalam penelitian ini adalah pengunjung Taman Rekreasi dan responden dipilih berdasarkan kerangka sampling sebagai berikut :

Tabel 3

Kerangka Sampling

\begin{tabular}{|l|l|l|}
\hline No & Kriteria & Alasan \\
\hline 1. & $\begin{array}{l}\text { Pengunjung } \\
\text { Domestik }\end{array}$ & $\begin{array}{l}\text { Pengunjung asing sangat } \\
\text { sedikit sehingga }\end{array}$ \\
\hline
\end{tabular}

Berdasarkan internal survey TIJA 2002 teridentifikasi bahwa $53 \%$ pengunjung Taman Rekreasi menyatakan pernah berkunjung di ketiga Taman Rekreasi. Selain itu, mayoritas pengunjung Taman Rekreasi merupakan pengunjung dewasa (TIJA 72\%, TMII 80\%, TMR 81\%) dan pengunjung ulang (TIJA 82\%, TMII 65\%, TMR 53\%). Dengan berpedoman pada rumus jumlah sampel minimal, kerangka sampling dan karakteristik pengunjung tahun 2002, maka jumlah sampel penelitian adalah sebesar: TIJA $=280$ responden, $\mathrm{TMII}=80$ responden, dan TMR $=69$ responden (total $=429$ responden). Teknik pengumpulan data dilakukan melalui observasi, wawancara, dan kuesioner yang ditujukan kepada 429 responden.

\section{HASIL PENELITIAN DAN PEMBAHASAN}

Berdasarkan analisis deskriptif, berikut rincian kinerja semua variabel penelitian :

1) Kinerja Value Creation masih rendah $(2,9)$ yang dilatarbelakangi oleh masih rendahnya kinerja dimensi core competency $(2,2)$ dan time compression $(2,7)$; 


\section{StrategiC}

2) Kinerja Bauran Promosi masih rendah (2,9) yang dilatarbelakangi oleh masih rendahnya kinerja dimensi public relation $(2,6)$ dan personal selling $(2,8)$;

3) Kinerja Bukti Jasa masih rendah $(2,8)$ yang dilatarbelakangi oleh masih rendahnya kinerja dimensi process $(2,4)$ dan people $(2,7)$;

4) Kinerja Citra Taman Rekreasi masih rendah $(2,9)$ yang dilatarbelakangi oleh masih rendahnya kinerja dimensi perceived quality

$(2,5)$ dan brand distinctiveness $(2,6)$.

Analisis verifikatif secara simultan membuktikan bahwa kinerja variabel bebas berpengaruh terhadap citra Taman Rekreasi, dan besarnya koefisien pengaruh adalah sebagai berikut :

Tabel 4

Koefisien Pengaruh Kinerja Value Creation (X1),

Bauran Promosi (X2), dan Bukti Jasa (X3)

Terhadap Citra Taman Rekreasi $(Y)$

\begin{tabular}{|c|c|c|c|c|c|}
\hline \multirow{3}{*}{ Variabel } & \multicolumn{5}{|c|}{ Pengaruh } \\
\cline { 2 - 5 }
\end{tabular}

Sumber: Hasil Pengolahan Data 2009

Analisis verifikatif secara parsial juga membuktikan bahwa masing-masing variabel bebas, berpengaruh terhadap citra Taman Rekreasi. Berdasarkan analisis verifikatif secara parsial dapat diidentifikasi besarnya pengaruh masing-masing dimensi terhadap citra Taman Rekreasi. Selanjutnya, dimensi yang memiliki pengaruh kuat dipilih sebagai dimensi solusi untuk peningkatan citra Taman Rekreasi sebagaimana tergambar pada tabel berikut.

Tabel 5

Rekapitulasi Total Pengaruh Masing-

Masing Dimensi Value Creation,

Bauran Promosi, dan Bukti Jasa terhadap Citra Taman Rekreasi

\begin{tabular}{|l|l|c|c|}
\hline \multicolumn{1}{|c|}{ Variabel } & \multicolumn{1}{|c|}{ Dimensi } & $\begin{array}{c}\text { Total } \\
\text { Pengaruh }\end{array}$ & Keterangan \\
\hline $\begin{array}{l}\text { Value } \\
\text { Creation }\end{array}$ & $\begin{array}{l}\text { Time } \\
\text { Compression }\end{array}$ & $6,6 \%$ & \\
\hline & Core Competency & $23,3 \%$ & Dimensi Solusi \\
\hline & $\begin{array}{l}\text { Continuous } \\
\text { Improvement }\end{array}$ & $15,1 \%$ & Dimensi Solusi \\
\hline & Relationship & Trimming & \\
\hline
\end{tabular}

\begin{tabular}{|l|l|c|c|}
\hline \multicolumn{1}{|c|}{ Variabel } & \multicolumn{1}{|c|}{ Dimensi } & $\begin{array}{c}\text { Total } \\
\text { Pengaruh }\end{array}$ & Keterangan \\
\hline $\begin{array}{l}\text { Bauran } \\
\text { Promosi }\end{array}$ & Personal Selling & $7,6 \%$ & \\
\hline & Advertising & $15,7 \%$ & Dimensi Solusi \\
\hline & Sales Promotion & Trimming & \\
\hline & Public Relation & $6,3 \%$ & \\
\hline & $\begin{array}{l}\text { Event \& } \\
\text { Experience }\end{array}$ & $8,1 \%$ & \\
\hline & Direct Marketing & $3,3 \%$ & \\
\hline Bukti Jasa & People & $14,3 \%$ & Dimensi Solusi \\
\hline & Process & $7,1 \%$ & \\
\hline & $\begin{array}{l}\text { Physical } \\
\text { Evidence }\end{array}$ & $41,3 \%$ & Dimensi Solusi \\
\hline
\end{tabular}

Sumber : Pengolahan Data 2009

Berdasarkan ke-5 dimensi solusi tersebut dapat dirumuskan faktor solusi (indikator solusi) untuk memecahkan masalah peningkatan citra Taman Rekreasi. Setelah dilakukan sinkronisasi, maka indikator/faktor solusi tersebut terdiri dari : peningkatan sumber daya teknologi (dimensi core competency), peningkatan pelayanan dan feedback management (dimensi continuous improvement), kejelasan pesan dan frekuensi iklan (dimensi advertising), peningkatan attitude dan aptitude petugas (dimensi people), penigkatan area hijau dan tampilan fisik (dimensi physical evidence) sebagaimana tergambar pada Peta Strategi Peningkatan Citra Taman Rekreasi dan Pengembangan Citra Jakarta sebagai Green City. 


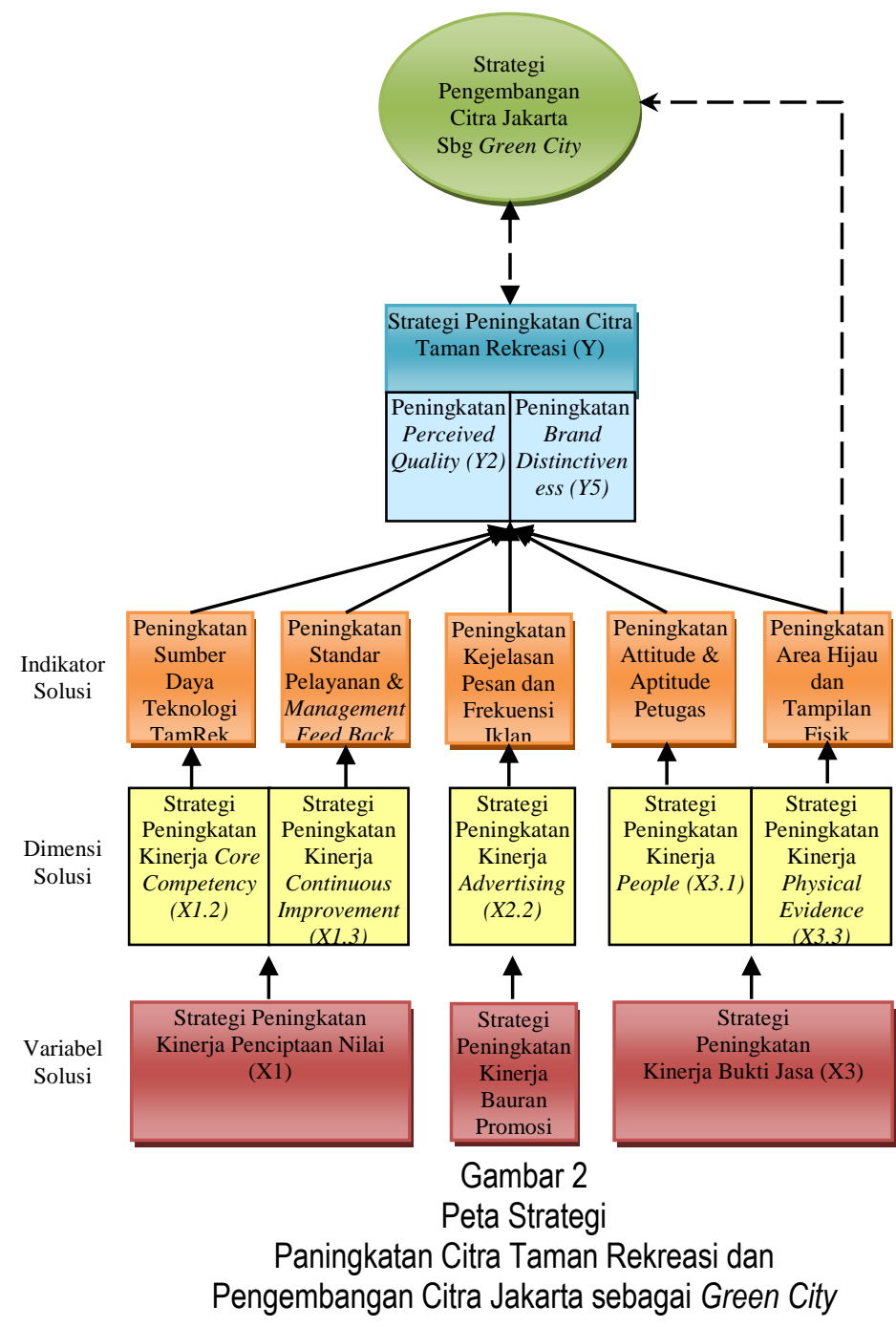

Hasil analisis verifikatif menunjukkan bahwa bukti jasa, khususnya dimensi physical evidence merupakan dimensi pengaruh yang paling dominan terhadap citra Taman Rekreasi. Dalam rangka pemecahan masalah peningkatan citra Taman Rekreasi, faktor solusi yang mendapat prioritas untuk ditingkatkan kinerjanya adalah area hijau dan tampilan fisik Taman Rekreasi. Hal ini mengindikasikan bahwa pengunjung menghendaki agar fungsi Taman Rekreasi sebagai pelestari lingkungan diperkuat.

Setelah dielaborasi secara mendalam, ternyata kedua faktor (indikator) solusi tersebut bersentuhan dengan konsep gren tourism. Charles Lockwood menyatakan bahwa konsep green building merupakan konsep pembangunan property / fasilitas fisik yang sesuai dengan tuntutan lingkungan. Beberapa kriteria yang dikembangkan Lockwood mencakup antara lain : proporsi ruang terbuka (open space) yang memadai, lanscape for saving (taman yang indah yang berfungsi juga sebagai paru-paru kota dan resapan air), implementasi green mindset dalam pembangunan fasilitas fisik, menghindari pemborosan energi dan kerusakan ozon (Lockwood, Building the Green Way, Harvard Business Review, 2007 : 1-20). Zeithaml, Bitner, Gremler (2006:317) menyatakan bahwa fasilitas fisik adalah semua hal yang ikut mempengaruhi keputusan konsumen untuk mengkonsumsi produk ljasa, termasuk kualitas udara, atmosfir, suara, aroma, dan tata ruang.

Dalam rangka pengembangan citra Jakarta sebagai green city, maka kedua faktor solusi tersebut dapat diadopsi dan perlu diterjemahkan ke dalam elemen operasional untuk dapat diterapkan di level perkotaan, yaitu sebagai berikut :

1) Peningkatan RTH (Ruang Terbuka Hijau) sampai dengan sekurang-kurangnya 13,94\% pada tahun 2010 untuk peningkatan sarana resapan air, menciptakan udara segar, dan menambah keindahan kota;

2) Peningkatan Tampilan fisik

a) Perbaikan drainase (saluran air) untuk mencegah / mengurangi bencana banjir tahunan;

b) Pengelolaan sampah terpadu untuk meningkatkan kesehatan masyarakat, keindahan kota, dan menciptakan peluang ekonomi dari pengolahan sampah organik maupun anorganik;

c) Uji emisi kendaraan bermotor untuk mengurangi polusi udara;

d) Peningkatan social basic elements masyarakat melalui pelaksanaan sosialisasi Sadar Wisata;

e) Perbaikan kondisi transportasi umum yang nyaman dan murah untuk mengurangi kemacetan lalu lintas, misalnya melalui percepatan program MRT (mass rapid transit), monorail, dan waterway;

Peningkatan sarana pencegahan banjir melalui percepatan realisasi program Banjir Kanal Timur (BKT) serta peningkatan fungsi situ penampungan air di wilayah DKI Jakarta. 


\section{KESIMPULAN DAN SARAN}

\section{Kesimpulan}

1. Temuan hasil penelitian menunjukkan bahwa kinerja Value Creation, Bauran Promosi, Bukti Jasa, dan Citra Taman Rekreasi masih rendah yang dilatarbelakangi oleh rendahnya kinerja dimensi : core competency dan time compression (variabel penciptaan nilai), public relation (variabel bauran promosi), people dan process variabel bukti jasa), perceived quality dan brand distinctiveness (variabel citra);

2. Temuan hasil penelitian membuktikan bahwa kinerja Penciptaan Nilai (Value Creation), Bauran Promosi (Promotion Mix), dan Bukti Jasa (the Evidence of Service) berpengaruh terhadap Citra (Company Image) Taman Rekreasi, baik secara simultan maupun parsial. Dimensi yang berpengaruh dominan adalah : dimensi core competency dan continuous improvement (variabel penciptaan nilai), dimensi advertising (variabel bauran promosi), dimensi people dan physical evidence (variabel bukti jasa)

3. Area hijau dan tampilan fisik merupakan faktor solusi yang bersentuhan dengan konsep green tourism yang dapat diadopsi untuk mendorong pengembangan citra Jakarta sebagai green city. Selanjutnya kuatnya citra Jakarta sebagai green city (citra destinasi) akan memperkuat citra Taman Rekreasi (citra daya tarik wisata), begitu juga sebaliknya.

\section{Saran}

1. Taman Rekreasi hendaknya terus menigkatkan citranya untuk menjaga keberlangsungan bisnisnya (sustainalibility) dengan cara meningkatkan sumber daya teknologi, meningkatkan kejelasan pesan iklan dan frekuensi penayangan iklan, peningkatan attitude dan aptitude sumber daya manusia, peningkatan kualitas area hijau dan tampilan fasilitas fisik;

2. Penelitian ini membahas peningkatan citra Taman Rekreasi berdasarkan perspektif pengunjung. Disarankan agar penelitian lanjut dapat menambahkan perspektif lain, misalnya perspektif pengelola / pelaku bisnis
Taman Rekreasi. Disarankan pula agar dilakukan penyempurnaan model penelitian dengan memasukkan variabel green tourism sebagai variabel penelitian yang diverifikasi;

3. Diharapkan agar Dinas Pariwisata dan Kebudayaan Provinsi DKI Jakarta dapat memelopori inisiatif untuk memanfaatkan hasil penelitian ini dan mendorong kerjasama dengan instansi dan industri terkait dalam rangka merumuskan kebijakan dan rencana tindak realisasi pengembangan Jakarta sebagai Green City.

\section{DAFTAR PUSTAKA}

Aaker, David A. 1991. Managing Brand Equity : Capitalizing on the Value of a Brand Name, The Free Press, New York, USA.

Cravens, David W. 2003. Marketing Strategic. McGraw Hill, New York, USA.

Dinas Pariwisata DKI Jakarta. 2008. Laporan dan Analisis Data Kepariwisataan, Jakarta, Indonesia.

Goodman, Steven. 2004. Competitive Benefit : An Outcome Approach to Marketing in the New Economy, British Academy of Management Conference Proceedings, Leeds Business School.

Gronroos, Christian. 2007. Service Management and Marketing : Customer Management in Service Competition, Third Edition, John Wiley \& Sons, Ltd., UK.

Harvard Business Review on Green Marketing Strategy . 2007

Keller, Kevin Lane. 2003. Strategic Brand Management : Building, Measuring, and Managing brand Equity, second Edition, Pearson Education, Inc., New Jersey, USA.

Kotler, Philip; Amstrong, Gary. 2006. Principles of Marketing, Pearson Education, Inc., Eleventh Edition, New Jersey, USA.

Kotler, Philip; Keller, Kevin Lane. 2009. Marketing Management, Pearson Prentice Hall, 13rd Edition, New Jersey, USA.

Kusnendi. 2005. Analisis Jalur: Konsep dan Aplikasi dengan Program SPSS \& LISREL,. Badan Penerbit: Jurusan 
Pendidikan Ekonomi (JPE) FPIPS.

Universitas Pendidikan Indonesia.

Bandung.

Lovelock, Christopher H; Wirtz, Jochen. 2007. Services Marketing : People, Technology, Strategy, Pearson Prentice Hall, Fifth Edition, USA.

Mowforth, Martin; Munt, lan. 1998. Tourism and Sustainability, Routledge, UK.

Peraturan Daerah Provinsi DKI Jakarta No 10 Tahun 2004 tentang Kepariwisataan, Jakarta, Indonesia.

PT. Pembangunan Jaya Ancol. 2002. Profil Pengunjung, Jakarta, Indonesia.

Swarbrooke, John; Horner, Susan. 2007. Cosumer Behavior in Tourism, Elsevier, New York, USA.

Undang-Undang Republik Indonesia Nomor 10 Tahun 2009 tentang Kepariwisataan, Jakarta, Indonesia.

Undang-Undang Republik Indonesia Nomor 18 Tahun 2008 tentang Pengelolaan Sampah.

Undang-Undang Republik Indonesia Nomor 26 Tahun 2007 tentang Tata Ruang.

Zeithaml, Valarie A; Bitner, Mary Jo; Gremler, Dwyne D. 2006. Services Marketing : Integrating Customer Focus Across the Firm, McGraw Hill International Edition, Fourth Edition, Singapore.

Zikmund, William G. 2003. Business Research Methods, Thompson South-Western, Seventh Edition, Ohio, USA. 